\title{
Minimum acceptable diet practice and its associated factors among children aged 6-23 months in rural communities of Goncha district, north West Ethiopia
}

\author{
Bamlaku Birie ${ }^{1 *}$, Andargachew Kassa $^{2}$, Emnet Kebede $^{2}$ and Bezabih Terefe ${ }^{3}$
}

\begin{abstract}
Background: After the first 6 months breast milk is no longer sufficient to meet the nutritional needs of the infant Therefore, complementary foods should be added to the child's diet. Feeding children with a diversified diet is practiced improperly in developing countries including Ethiopia particularly in the rural community of the Amhara region. However, limited information was documented on the rural communities and no data were available specifically in the study area to show the exact picture of child feeding practices. So, this study was planned to assess minimum acceptable diet practice and its associated factors among children aged 6-23 months in the rural community of Goncha district, Amhara region, Ethiopia.
\end{abstract}

Methods: Community-based cross-sectional study was employed to determine minimum acceptable diet practice and its associated factors among children aged 6-23 months at rural communities of Goncha district, East Gojjam zone, Amhara region, Ethiopia. A multi-stage sampling technique was used to select study subjects, and an interview administered structured questionnaire was used to collect the data. Data were entered by Epi Data version 4.0.2 and exported to SPSS 20 for analysis. Bivariate and multivariable logistic regression analysis was used to see the association. Then, $P$-value $<0.05$ with $95 \% \mathrm{Cl}$ on multivariable logistic regression analysis were used to identify the predictor of the outcome variable.

Results: A total of 430 mothers who have children aged 6-23 months were included in the analysis with a 98\% of response rate. About $12.6 \%$ of children aged $6-23$ months received the recommended minimum acceptable diet. Children whose mothers who had formal education $[\mathrm{AOR}=2.7,95 \% \mathrm{Cl}(1.133,6.231)]$, institutional delivery $[\mathrm{AOR}=$ $4.5,95 \% \mathrm{Cl}(1.986,10.362)]$, media exposure $[\mathrm{AOR}=2.6,95 \% \mathrm{Cl}(1.303,5.291)]$ and higher household wealth index $[A O R=2.5,95 \% \mathrm{Cl}(1.139,5.90)]$ were significantly associated with minimum acceptable diet.

Conclusion: The practice of minimum acceptable diet in the study area was inadequate and very low according to the national recommendation. So, strengthening institutional delivery, improving the wealth of the community and exposure to media, and finally empowering women's' for education is recommended.

\footnotetext{
* Correspondence: bamlakubirie21@gmail.com

'Department of Midwifery, College of Medicine and Health science, Mizan

Tepi University, Mizan Aman, Ethiopia

Full list of author information is available at the end of the article
}

\section{$\triangle B M C$}

C C The Author(s). 2021 Open Access This article is licensed under a Creative Commons Attribution 4.0 International License, which permits use, sharing, adaptation, distribution and reproduction in any medium or format, as long as you give appropriate credit to the original author(s) and the source, provide a link to the Creative Commons licence, and indicate if changes were made. The images or other third party material in this article are included in the article's Creative Commons licence, unless indicated otherwise in a credit line to the material. If material is not included in the article's Creative Commons licence and your intended use is not permitted by statutory regulation or exceeds the permitted use, you will need to obtain permission directly from the copyright holder. To view a copy of this licence, visit http://creativecommons.org/licenses/by/4.0/ The Creative Commons Public Domain Dedication waiver (http://creativecommons.org/publicdomain/zero/1.0/) applies to the data made available in this article, unless otherwise stated in a credit line to the data. 


\section{Introduction}

Sufficient nutrition in the earlier months of life is key to health and growth, and its importance goes throughout life [1]. Later six months breast milk is no longer adequate to meet the nutritional needs of the infant. Therefore, additional foods should be introduced to the child's diet, which is the transition from exclusive breastfeeding to family foods. This is the most critical period because children are most susceptible to malnutrition during this transition [2].

A minimum acceptable diet (MAD) is an indicator for evaluating child feeding practices presented via World Health Organization. It is a combination of the minimum dietary diversity and minimum meal frequency [3]. Infants and young children should have a minimum acceptable diet (MAD) to ensure appropriate growth and development, otherwise, they are vulnerable to undernutrition especially stunting and micronutrient deficiencies, and increased morbidity and mortality $[1,4]$. In addition to a lack of adequate and balanced diet, several people are attacked by diseases that occur due to proteinenergy malnutrition and due to lack of diseaseprotecting foods. Children, pregnant women, and lactating mothers are most vulnerable to this problem [5].

Also, it is known that nutrition is one of the vital preconditions for achieving sustainable development goals because, from 17 SDGs, the first three icons are directly related to nutrition [6].

Although Ethiopia is a manufacturer of a diversity of agricultural products, still the countries are known in the world with the highest number of malnourished populations. Malnutrition is primarily seen among rural residents and the prevalence among children was $48.5 \%$ [7]. The Ethiopian government has been tried to improve child feeding practices by implementing the national nutrition program of child feeding practices and a multi-sectoral plan of nutrition intervention to end child undernutrition in Ethiopia by 2030 [8]. Despite this, the progress was not satisfactory, particularly the national prevalence of MAD practice was 7\%. The burden is higher in rural areas and significant variation also exists between regions. Children in urban areas (19\%) are more likely to feed than those in rural areas (6\%) and the proportion of children who receive the minimum acceptable diet is highest (27\%) in Addis Ababa and lowest (2\%) in Amara region [2, 9].

Even though studies were conducted about the determinants of the optimal complementary feeding practices in Ethiopia, however, inadequate efficient information was documented about minimum acceptable diet practice and its associated factors independently and most of the studies were not representative especially for rural communities. Also, as far as the researcher's knowledge is concerned, no documented data were accessible specifically in the study area. Therefore, this study was planned to assess minimum acceptable diet practice and its associated factors among children aged between 6 and 23 months in rural communities of Goncha district, Amhara region, Ethiopia during the year 2020. Finally, the findings of this study will help to identify high-risk groups in the formulation of appropriate complementary feeding interventions.

\section{Methods}

Study area and period

A community-based cross-sectional study was employed from June 15 to July 152,020 in rural communities of Goncha district, which is located in East Gojjam Zone, Amhara region, Ethiopia. The woreda (administrative division in Ethiopia) is located $154 \mathrm{~km}$ East of Bihar Dar, the capital city of the Amhara region, and $335 \mathrm{~km}$ far from the Northwest of Addis Ababa. This woreda is administratively structured by 43 Keble's (lowest administrative division in Ethiopia) 41 rural and 2 urban Keble's. Of these rural Keble's 12 are lowlands and 29 are highlands. Almost all of the district's population consists of subsistence farmers heavily depending on rains for their agriculture. The district is one of the areas in the region, known to experience chronic food insecurity due to variable rainfall pattern, and the population especially who are resided in lowland Keble's are users of government safety net program. In the woreda, there are 8 governmental health centers with the ratio of one health center to five Keble's and 43 health posts. Goncha woreda is settled by total populations of 210,423 , of these 108,909 are females and 42,569 are in the reproductive age group (15-49). Out of the total population 28, 491 are underfive children's and 10,626 (5\% of the total population) are infants and young children aged 6-23 months (Goncha woreda health office annual report, 2012 E.C).

\section{Study participants}

Children aged 6-23 months with mothers who are residents of the selected Keble's at least 6 months and available during the data collection period were included. Children of mothers who were seriously ill during the data collection period and children having acute illness and other conditions which disturb appetite during the survey (determined by respondents' self-report and by observation) were excluded.

\section{Sample size determination}

The sample required for this study was calculated using single population proportion formula; by considering the following assumptions: $\mathrm{Z}=$ standard normal distribution $(Z=1.96)$ with a confidence interval of $95 \%, p=8.6 \%$ taken from a proportion of MAD in Dembecha district [10], $\mathrm{d}=$ tolerable margin of error $(\mathrm{d})=0.038$, by adding 
2 design effect and 5\% non-response rate, the total sample size required for this study was $=439$. To ensure the adequacy of sample size, Epi info was used to calculate sample size for factors associated with minimum acceptable diet.

\section{Sampling procedure}

A multi-stage sampling technique was used to select the study subjects. First total rural Keble's in Goncha district were stratified into highland (dega) and lowlands (kola) based on their predominating agroecological characteristics (classification obtained from Goncha woreda health office). Second, from the two strata, 8 from 29 highland Keble's and 4 from 12 lowlands Keble's were selected by using the lottery method. Then, the total sample size was allocated proportionally and sampling interval- " $K$ " was determined. Finally, 439 children aged 6-23 months were selected by using a systematic sampling method based on the sampling frame obtained from Health Extension Worker's (HEW's) record. After randomly identified the first child, we preceded the second child every 4 intervals (Fig. 1).

\section{Dependent variable}

Minimum acceptable diet.

\section{Operational definitions}

Minimum acceptable diet

Proportion of children's aged 6-23 month who had at least minimum meal frequency and minimum diversified diet during the previous day [11].

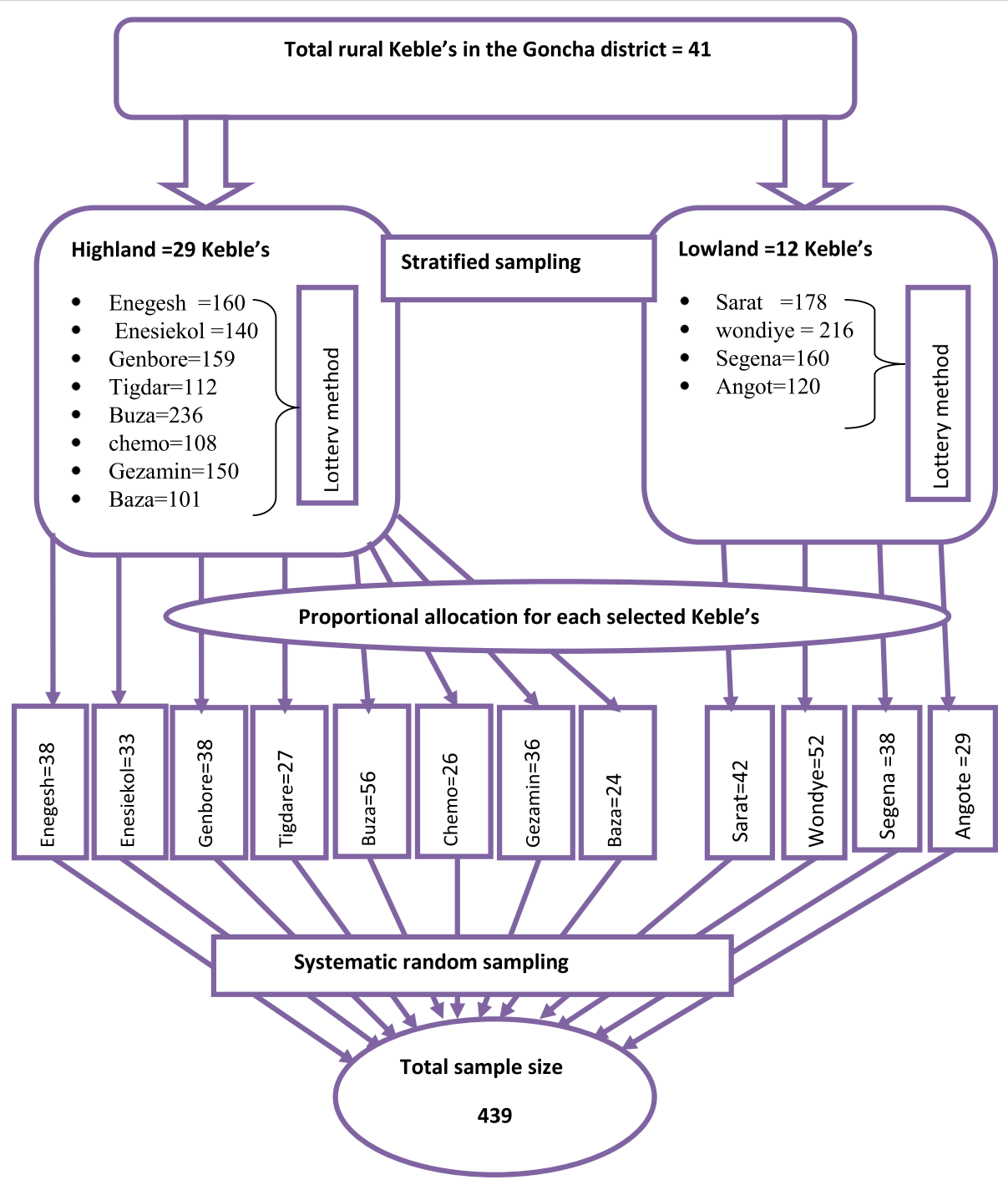

Fig. 1 Schematic presentation of sampling procedure from total rural Keble's, in Goncha district, Northwest Ethiopia, 2020 


\section{Minimum meal frequency}

Proportion of breastfeeding and non-breastfeeding children aged 6-23 months who receive soft, solid, and semi-solid foods (but also including milk feeds for nonbreast feed children) in the last $24 \mathrm{~h}$. Breastfeed infants aged 6-8 months 2 times in the last $24 \mathrm{~h}$; breastfeed infants and young children aged 9-23 months 3 times in the last $24 \mathrm{~h}$. For non-breastfeeding infants and young children aged 6-23 months at least 4 times in the last $24 \mathrm{~h}$ [3].

\section{Minimum dietary diversity}

Proportion of children aged 6-23 months who receive five or more food groups out of the eight food groups in the last $24 \mathrm{~h}$. These foods groups used for this indicator are breast milk, grains, roots and tubers; legumes and nuts; dairy products (milk, yogurt); Flesh foods (meat, fish, poultry, and liver/organ meats); eggs; vitamin Arich fruits and vegetables; and other fruits and vegetables. Quality and quantity of any amount from those groups can be considered as sufficient to count [11].

\section{Maternal knowledge on IYCF practice}

Knowledge of mothers on infant and child feeding practice was measured based on ten knowledge questions. Each correct answer (yes) earned one point, and any wrong answer (no) got zero. The calculated knowledge score ranged from 0 to 10 points. Those who score above the mean $(5.7 \pm 2.6$ standard deviations $)$ was categorized as knowledgeable and those who score below the mean was categorized as not knowledgeable [12].

\section{Exposure to media}

Media exposure was categorized as satisfactory or unsatisfactory. Mothers who listen to the radio, or watched television at least once a week was satisfactory media exposure, and otherwise unsatisfactory [13].

\section{Data collection and quality control}

Primary data was collected using intervieweradministered and structured questionnaires from selected children of mothers through a face-to-face interview. 8 data collectors and 2 supervisors have participated in the survey. Questionnaires were prepared in English and were translated into the local language (Amharic), and again it was translated back into English to keep its consistency. Data collectors were trained for one day before the data collection period. The collected data was checked regularly by supervisors and principal investigators for its completeness and consistency.

\section{Data processing and analysis}

Data were entered by using Epi Data entry client version 4.0.2 and exported to SPSS 20 statistical package for analysis. Data cleaning was performed to check for consistencies and values. Dietary diversity score was computed out of eight from eight food groups, and household economic status was measured by constructing wealth index through principal component analysis (PCA) and ranked as low, middle, and high wealth index. Tables and graphs were used for data presentation. Bivariate logistic regression analysis was done to see the association of independent variables on the dichotomous outcome variable. To control the effect of potential confounders and to identify the independent effect of the explanatory variable on the minimum acceptable diet, variables with a $p$-value less than 0.25 in bivariate logistic regression were considered as a candidate for multivariable logistic regression analysis. Before going on multivariable logistic regression analysis multicollinearity was checked by co-linearity diagnostic tests and variables with variance inflation factor (VIF) less than ten, and variables that fulfill sample size assumptions were entered into the model. At this level, model fitness was checked with Hosmer and Lemeshow goodness of fit at a $p$-value $\geq$ of 0.05 . Finally, variables with a $\mathrm{p}$-value less than 0.05 and $95 \% \mathrm{CI}$ were considered as the predictive for the outcome variable. The strength of associations and statistical significances between independent variables and outcome variables were expressed using OR and $95 \%$ confidence interval respectively.

\section{Result}

\section{Socio-demographic characteristics}

Among a total of 439 sampled subjects, 430 children aged between 6 and 23 months with mothers were enrolled in the study making a response rate of $98 \%$. Among children aged 6-23 months, 217 (50.5\%) were females and 167(38.8\%) were categorized in the age group between 18 and 23 months. The mean age of children was $15.3 \pm 5.4$ (SD) months, and half of the children aged 6-23 months were in the birth order of second to fourth 218(50.7\%). Concerning the educational status of children's parents, About 283 (65.8\%) and 262(60.9\%) of mothers and fathers had no formal education respectively. From total children parents, about three fourth $320(74.4 \%)$ of fathers were farmers followed by merchants 56(13.0\%). (Table 1).

\section{Maternal and child health care utilization}

During the pregnancy of sampled child, less than half $181(42.1 \%)$ of mother attended four and above times antenatal care visits, and more than half $262(60.9 \%)$ of mothers did not utilize postnatal care service. Out of the total children aged 6-23 months, the majority (60.5\%) of children were delivered at home, and about a quarter 113(26.3\%) of children aged 6-23 months did not start vaccination. Nearly all, 426(99.1\%) of children aged 6- 
Table 1 Parental level socio-demographic characteristics of children aged 6-23 months, Goncha, Northwest Ethiopia, 2020 ( $n=430)$

\begin{tabular}{|c|c|c|c|}
\hline Characteristics & Category & Frequency(n) & Percentage (\%) \\
\hline \multirow[t]{3}{*}{ Mother age (years) } & $15-24$ & 121 & 28.1 \\
\hline & $25-34$ & 206 & 47.9 \\
\hline & $35-49$ & 103 & 24.0 \\
\hline \multirow[t]{4}{*}{ Marital status } & Married & 365 & 84.9 \\
\hline & Divorced & 28 & 6.5 \\
\hline & Single & 25 & 5.8 \\
\hline & Other $^{a}$ & 12 & 2.8 \\
\hline \multirow[t]{2}{*}{ Mother education } & No formal education & 283 & 65.8 \\
\hline & Formal education & 147 & 34.2 \\
\hline \multirow[t]{2}{*}{ Father education } & No formal education & 262 & 60.9 \\
\hline & Formal education & 168 & 39.1 \\
\hline \multirow[t]{4}{*}{ Mother Occupation } & Farmer & 173 & 40.2 \\
\hline & Housewife & 182 & 42.3 \\
\hline & Merchant & 56 & 13.0 \\
\hline & Other $^{b}$ & 19 & 4.5 \\
\hline \multirow[t]{4}{*}{ Father Occupation } & Farmer & 320 & 74.4 \\
\hline & Merchant & 56 & 13.0 \\
\hline & Employee & 40 & 9.3 \\
\hline & Other $^{c}$ & 14 & 3.3 \\
\hline \multirow[t]{2}{*}{ Sex of a child } & Male & 213 & 49.5 \\
\hline & Female & 217 & 50.5 \\
\hline \multirow[t]{3}{*}{ Age of child in month } & $6-11$ & 123 & 28.6 \\
\hline & $12-17$ & 142 & 33.0 \\
\hline & $18-23$ & 165 & 38.4 \\
\hline \multirow[t]{3}{*}{ Birth order of a child } & First & 132 & 30.7 \\
\hline & Second to fourth & 218 & 50.7 \\
\hline & Above fourth & 80 & 18.6 \\
\hline \multirow[t]{2}{*}{ Agroecology } & Dega & 230 & 53.5 \\
\hline & Kola & 200 & 46.5 \\
\hline
\end{tabular}

${ }^{a}$ died/separated, blabor work/no current work/employer, ' labor work/no current work

23 months were breastfed at the time of data collection, and around one-third, 148(34.4\%) of 6-23 month aged children were started complementary food after six months. Greater than three fourth, 341(79.3\%) of children did not receive monthly growth monitoring and promotion service. (Table 2).

\section{Mothers knowledge on child feeding practice and household level related characteristics}

Concerning the knowledge of mothers on infant and young child feeding practice, greater than half, $253(58.8 \%)$ of mothers were knowledgeable. Out of the total study participants, one-third $138(32.1 \%)$ of children were living in houses where family members greater than five. Of the mothers of children aged 6-23 months, two-thirds $284(66 \%)$ of mothers participated in the household decision, and about one-third 140(32.6\%) of mothers had satisfactory media exposure (see Table 3).

\section{Minimum acceptable diet practice}

From total children aged 6-23 months, about 54(12.6\%) of children meet the recommended minimum acceptable diet.

Factors influencing minimum acceptable diet practice To identify factors associated with minimum acceptable diet practice, bivariate and multivariable logistic regression analyses were done. On binary logistic regression analysis variables with $p$-value, less than 0.25 were considered as a candidate for multivariable logistic regression analysis. Finally, variables with a p-value less than 0.05 and $95 \%$ CI i.e. mother education, place of delivery, 
Table 2 Maternal and child healthcare-related characteristics of children aged 6-23 month, Goncha, Northwest Ethiopia, 2020 $(n=430)$

\begin{tabular}{|c|c|c|}
\hline Characteristics & Frequency(n) & Percentage (\%) \\
\hline \multicolumn{3}{|l|}{ Antenatal service } \\
\hline Fourth and above visit & 181 & 42.1 \\
\hline One to three visit & 117 & 27.2 \\
\hline No visit & 132 & 30.7 \\
\hline \multicolumn{3}{|l|}{ Place of delivery } \\
\hline Home & 260 & 60.5 \\
\hline Health facility & 170 & 39.5 \\
\hline \multicolumn{3}{|l|}{ Post natal care } \\
\hline Within 7 day & 44 & 10.2 \\
\hline After 7 days & 124 & 28.9 \\
\hline No visit & 262 & 60.9 \\
\hline \multicolumn{3}{|l|}{ Pre lacteal feeding } \\
\hline Yes & 207 & 48.1 \\
\hline No & 223 & 51.9 \\
\hline \multicolumn{3}{|l|}{ Vaccination status } \\
\hline Vaccinated/started & 317 & 73.7 \\
\hline Not started & 113 & 26.3 \\
\hline \multicolumn{3}{|l|}{ first, breastfeed for a child } \\
\hline Within $1 \mathrm{~h}$ & 156 & 36.3 \\
\hline After $1 \mathrm{~h}$ & 274 & 63.7 \\
\hline \multicolumn{3}{|l|}{ Current Brest feeding status } \\
\hline Breastfeeding & 426 & 99.1 \\
\hline Not breastfeeding & 4 & .9 \\
\hline \multicolumn{3}{|c|}{ Time of starting complementary food } \\
\hline Before 6 months after delivery & 87 & 20.2 \\
\hline At 6 months & 147 & 34.2 \\
\hline After 6 months & 148 & 34.4 \\
\hline I do not know & 48 & 11.2 \\
\hline \multicolumn{3}{|c|}{ Growth monitoring and promotion service } \\
\hline No & 341 & 79.3 \\
\hline Yes & 89 & 20.7 \\
\hline
\end{tabular}

exposure to media, and wealth index were found to be the potential predictors of meeting minimum acceptable diet (See Table 4).

\section{Discussion}

The finding of this study revealed that $12.6 \%$ with $95 \%$ CI $(9.5,15.7)$ of children aged $6-23$ months were received the recommended minimum acceptable diet. This was higher compared to a study conducted in Northwest Ethiopia, Dembecha (8.6\%) [10]. The variation might be due to the different study periods. The above study was conducted in populations where only orthodox religion followers during the fasting season in which feeding
Table 3 maternal/caregiver knowledge on child feeding and household level related characteristics of children aged 6-23 months, Goncha, Northwest Ethiopia, 2020 ( $n=430)$

\begin{tabular}{lll}
\hline Characteristics & Frequency(n) & Percentage (\%) \\
\hline Maternal knowledge of IYCF & & \\
Knowledgeable & 253 & 58.8 \\
Not knowledgeable & 177 & 41.2 \\
Family size & & \\
$>5$ & 138 & 32.1 \\
$<=5$ & 292 & 67.9 \\
No of under-five children within a household & \\
Two and above & 150 & 34.9 \\
One & 280 & 65.1 \\
Media exposure & & \\
Unsatisfactory & 290 & 67.4 \\
Satisfactory & 140 & 32.6 \\
Mother participation in household decision & \\
Mother not involved & 146 & 34.0 \\
Mother involved & 284 & 66.0 \\
Wealth index & & 34 \\
Low & 146 & 33 \\
Middle & 142 & 33 \\
High & 142 & \\
\hline
\end{tabular}

habits might be reduced either in food diversity, especially animal source foods, or meal frequency which underestimate the finding when compared to other periods. Also, the above study was conducted in the dry season what we call "winter" in which the nutritional availability of most fruits and vegetables might be low compared to seasons especially "summer" a period in which this study was conducted.

This finding was also higher than the EDHS report of 2016, only $7 \%$ of children aged 6-23 months received a minimum acceptable diet [2]. The difference might be due to EDHS were conducted on a culturally different population, which may underrate child feeding practices while this study was conducted on an almost culturally homogenous population with similar feeding practices. The results of this study were higher than studies conducted in Ethiopia multilevel analysis report of EDHS 2016 (6.1\%), Malawi (8.36\%), Nigeria (7.3\%), and Philippines $(6.7 \%)$ of children aged 6-23 months received the recommended minimum acceptable diet $[9,10,14-16]$. The reason for a high percentage of feeding practice in this study area might be due to variation in study design, data collection period, and nutrition education with media and health extension workers might play a major role in increasing community awareness towards appropriate child feeding practice [17]. 
Table 4 Bivariate and multivariable logistic regression output showing factors associated with minimum acceptable diet practice among children's aged 6-23 months, Goncha, Northwest Ethiopia, 2020, ( $n=430)$

\begin{tabular}{|c|c|c|c|c|c|}
\hline Variable & Category & $\begin{array}{l}\text { Not meet MAD } \\
\mathrm{N}(\%)\end{array}$ & $\begin{array}{l}\text { Meet MAD } \\
\mathrm{N}(\%)\end{array}$ & COR $(95 \% \mathrm{Cl})$ & AOR $(95 \% \mathrm{Cl})$ \\
\hline \multirow[t]{2}{*}{ Agro ecology } & Dega & $196(85.2)$ & $34(14.8)$ & $1.56(0.867-2.811)$ & $0.8(0.374-1.687)$ \\
\hline & Kola & $180(90)$ & $20(10)$ & 1 & 1 \\
\hline \multirow[t]{2}{*}{ Place of delivery } & Home & $249(95.8)$ & $11(4.2)$ & 1 & 1 \\
\hline & Health facility & $127(74.7)$ & $43(25.3)$ & $7.6(3.82-15.37)^{* *}$ & $4.5(1.98-10.36)^{* *}$ \\
\hline \multirow[t]{2}{*}{ Pre lacteal fed for a child } & No & $188(84.3)$ & $35(15.7)$ & 1 & 1 \\
\hline & Yes & $188(90.8)$ & $19(9.2)$ & $0.54(0.30-0.983)^{*}$ & $1.28(0.618-2.664)$ \\
\hline \multirow[t]{2}{*}{ PNC service } & No & $236(90.1)$ & $26(9.9)$ & 1 & 1 \\
\hline & Yes & $140(83.3)$ & $28(16.7)$ & $1.8(1.023-3.221)^{*}$ & $0.7(0.329-1.488)$ \\
\hline \multirow[t]{2}{*}{ Mother education } & No formal education & $268(94.7)$ & $15(5.3)$ & 1 & 1 \\
\hline & Formal education & $108(73.5)$ & $39(26.5)$ & $6.4(3.41-12.18)^{* *}$ & $2.7(1.133-6.231)^{*}$ \\
\hline \multirow[t]{2}{*}{ Father education } & No formal education & $245(93.5)$ & $17(6.5)$ & 1 & 1 \\
\hline & Formal education & $131(78)$ & $37(22)$ & $4.07(2.20-7.50)^{* *}$ & $1.6(0.71-3.677)$ \\
\hline \multirow[t]{2}{*}{ Family size } & $>5$ & $126(91.3)$ & $12(8.7)$ & 1 & 1 \\
\hline & $<=5$ & $250(85.6)$ & $42(14.4)$ & $1.76(0.897-3.469)$ & $1.4(0.613-3.098)$ \\
\hline \multirow[t]{2}{*}{ Decision making in household } & Mother not involved & $132(90.4)$ & $14(9.6)$ & 1 & 1 \\
\hline & Mother involved & $244(85.9)$ & $40(14.1)$ & $1.54(0.811-2.944)$ & $1.2(0.564-2.528)$ \\
\hline \multirow[t]{2}{*}{ Exposure to media } & Unsatisfactory & $270(93.1)$ & $20(6.9)$ & 1 & 1 \\
\hline & Satisfactory & $106(75.7)$ & $34(24.3)$ & $4.3(2.385-7.86)^{* *}$ & $2.6(1.303-5.29)^{* *}$ \\
\hline \multirow[t]{2}{*}{ Knowledge of mothers on IYCF practice } & Not knowledgeable & $169(95.5)$ & $8(4.5)$ & 1 & 1 \\
\hline & Knowledgeable & $207(81.8)$ & $46(18.2)$ & $4.7(2.157-10.2)^{* *}$ & $1.6(0.626-3.954)$ \\
\hline \multirow[t]{3}{*}{ Wealth index } & Low & $132(90.4)$ & $14(9.6)$ & 1 & 1 \\
\hline & Middle & $130(91.5)$ & $12(8.5)$ & $0.71(0.32-1.61)$ & $1.1(0.445-2.72)$ \\
\hline & High & $114(80.3)$ & $28(19.7)$ & $2.7(1.193-6.766)^{*}$ & $2.5(1.139-5.90)^{*}$ \\
\hline
\end{tabular}

Notice ${ }^{*} \mathrm{p}$-value $<0.05,{ }^{* *} \mathrm{p}$-value $<0.01$, COR- crude odds ratio, AOR- adjusted odds ratio,

On the other hand, the finding of this study was lower than a study done in wolayita Sodo town (Southern Ethiopia) $21.1 \%$ of children consumed a minimum acceptable diet [18]. The variation might be because of different study settings and study periods; this study was conducted in the rural communities whereas the above study was conducted in urban communities, as communities from rural areas are less likely to feed a minimum acceptable diet than people residing in the urban area [2]. Also, the difference might be due to higher noneducated mothers were participated in this study, on the contrary, higher numbers of educated participants were included in the above study. The result was also lower than the study conducted in different countries; Ghana, Uganda, and Kenya in which 29.9, 23.9, and $48.5 \%$ of children received recommended minimum acceptable diet, respectively [19-21]. Lower findings in this study area might be due to differences in study design, sample size, study period, and difference in socio-demographic characteristics. Also, the finding was low compared to the 2020 global nutrition report (18.9\%) [22]. The variation might be due to difference in sample size and socio-demographic characteristics.

Mother education was significantly associated with minimum acceptable diet practice. Based on this study, mothers who had formal education were 2.7 times more likely to provide minimum acceptable diets for their children compared to mothers who had no formal education. This finding was supported by a study done in Dembecha [10]. This might show that education enables mothers to know the benefits of the practice of child feeding and plays an important role in meeting minimum acceptable diet standards. However, this finding was not supported by the study done in North Shoa, Oromia region, and multilevel analysis report of EDHS $2016[9,23]$.

Children born in a health facility were 4.5 times more likely to receive a minimum acceptable diet than those born at home. This result was similar to a study done in Northwest Ethiopia [10]. This might be due to health professional counseling on appropriate child feeding after delivery on health facility increases mothers 
awareness on practice of minimum acceptable diet; Hence mother's awareness on appropriate child feeding practice who got from health professionals have had a better child feeding practices than their counterparts [17].

Children whose mothers were exposed to media i.e. watched television, listen to the radio every day or once a week, has 2.6 times more likely to meet the minimum acceptable diet than those children of mothers who watched television and listen to the radio less than once a week or not at all. This finding was similar to other findings in North Shoa, Oromia region, and multi-level analysis report of EDHS $2016[9,23]$. This might be because the currently Ethiopian ministry of health and its partners promote child feeding practices through radio, television, and family health cards. This might enhance the mother's awareness of feeding a minimum acceptable diet to their children. Also, this might be because mothers who have been exposed to the media have had better opportunities to access information on appropriate child feeding practices. This could improve the mother's capacity to challenge unfavorable information towards child feeding practices in the community and increase appropriate child feeding habits. On the other hand, this finding was not supported by the study conducted in Dembecha [10].

Children born from mothers with a high wealth index were 2.5 times more likely to receive the recommended minimum acceptable diet than children born from mothers with a low wealth index. This result was nearly similar to a study done in the Philippines [24], in which children born from mothers in the middle wealth index were more likely to meet the minimum acceptable diet compared to those children born from mothers in the poorest wealth index, The possible explanation of this significant association might be due to the limited food purchasing power to provide diversified diet to their children in peoples with lower wealth index, and also mothers in high wealth index were more likely provide nutritious food to their children compared to mothers from low wealth index households who were more focus on the quantity of food [11]. This finding was not supported by other studies conducted in Dembecha, North Shoa, and the multilevel analysis report of EDHS 2016 [9, 10, 23].

\section{Limitation}

This study only measures the diversity and frequency of foods given for children aged 6-23 months, but it is important to include the quantity of foods given for the child. Even if children who were sick were excluded, there might be children who were not known to sick or not sick in the previous one week, but who lost their appetite during data collection time, which could underestimate our finding. This study didn't consider seasonal variations during the data collection period, which might be affected feeding habits especially food diversity be affected.

\section{Conclusion}

Minimum acceptable diet practice among children aged 6-23 months in the study area was low, almost one from eight children meet the recommended minimum criteria. So, child feeding practices in the study area were not achieved the national infant and young child feeding recommendation. Determinant Factors that significantly affect meeting of minimum acceptable diet practice were the educational status of the mother, place of delivery, exposure to media, and household wealth index. This implies that the problems are range from individual to household level, and even may go through at large in the community level.

\section{Abbreviations}

AOR: Adjusted Odd Ratio; COR: Crude Odd Ratio; EDHS: Ethiopian

Demographic Health Survey; IYCF: Infant and young children feeding; MAD: Minimum Acceptable Diet; SPSS: Statistical Package for Social Science; UNICF: United Nations International Children Fund; WHO: World Health Organization

\section{Acknowledgments}

First of all, we would like to thank Hawassa University College of medicine and health science department of Midwifery for giving the chance to conduct this research. Also, our acknowledgment goes to Goncha woreda health office and health extension workers who are working in selected Keble's. Our thanks also go to data collectors, supervisors, and study participants.

\section{Authors' contributions}

Bamlaku Birie: Conceptualization, Development, and design of methodology entering data into computer software, data analysis, writing original draft, preparing the manuscript. Andargachew Kassa: Development and design of methodology, data analysis, Supervision, editing, read and approved the final manuscript. Emnet Kebede: Development and design of methodology, data analysis, supervision, writing original draft, read and approved the final manuscript. Bezabih Terefe: Development and design of methodology, data analysis, and preparing the manuscript.

Funding

Hawassa University.

Availability of data and materials

The datasets used during the current study are available from corresponding authors when reasonably desired.

\section{Declarations}

Ethics approval and consent to participate Ethical clearance was obtained from the Institutional Review Board of Hawassa University, College of Medicine and Health Sciences with reference No IRB/090/12. Permission letter was obtained from Hawassa University, College of Medicine and Health Sciences, department of midwifery and submitted to Goncha woreda administration and health offices. Informed consent was taken from the mothers. All methods were performed by the institutional guidelines.

Consent for publication

Not applicable.

Competing interests

The authors declared that no competing interests exist. 


\section{Author details}

'Department of Midwifery, College of Medicine and Health science, Mizan Tepi University, Mizan Aman, Ethiopia. ${ }^{2}$ Department of Midwifery, College of Medicine and Health Science, Hawassa University, Awassa, Ethiopia. ${ }^{3}$ Department of Midwifery, College of Medicine and Health Science, Arba Minch University, Arba Minch, Ethiopia.

Received: 11 December 2020 Accepted: 21 May 2021

Published online: 20 July 2021

\section{References}

1. Das Jai K, Salam Rehana A, Imdad Aamer A. BZ. Infant and young child growth. Reproductive, maternal, newborn, and child. Health. 2015

2. EDHS E. Demographic and health survey 2016: key indicators report. The DHS Program ICF. 2016.

3. WHO, UNICEF, USAID. Indicators for assessing infant and young child feeding practices: part 1: definitions: conclusions of a consensus meeting held 6-8 November 2007 in Washington DC, USA. 2008.

4. WHO U, USAID, FANTA, AED U, Indicators for assessing infant and young child feeding practices part 2: measurement. Geneva: The World Health Organization; 2010.

5. Adis Ababa. The Federal democratic republic of Ethiopia, Ministry of health. Ethiopia: Postnatal Care; 2003.

6. Health in from Millenium Development Goal to Sustainable Development Goals, Transform Our World. 2015.

7. Neima E, Henok A, Lamessa D. Prevalence of malnutrition and associated factors among children in rural Ethiopia. Biomed Res Int. 2017;2017.

8. Eyerusalem S, Biruk T. ending rural hunger the case of Ethiopia. Africa Growth Initiative at Brookings: 2017.

9. Abay AT, Yemane TD, Bekele BA, Meressa AB. Factors affecting feeding 6-23 months age children according to minimum acceptable diet in Ethiopia: A multilevel analysis of the Ethiopian Demographic Health Survey. PLoS One. 2019.

10. Efram M, Girma A, Wubetu W. Habtamu T. Uptake of minimum acceptable diet among children aged 6-23 months in orthodox religion followers during fasting season in rural area, DEMBECHA, north West Ethiopia. BMC Nutrition. 2019;5(1):18

11. $\mathrm{WHO}$, Global Nutritional Monitoring F. Operational guidance for tracking progress in meeting targets for 2025: World Health Organisation; 2017.

12. Solomon D, Zewdie A, Kassaw TT. Minimum dietary diversity and associated factors among children aged 6-23 months in Addis Ababa, Ethiopia. Int J Equity Health. 2017;16(1):181. https://doi.org/10.1186/s12939-017-0680-1.

13. Beyene M, Worku AG, Mesele MW. Dietary diversity, meal frequency and associated factors among infant and young children in Northwest Ethiopia: a cross-sectional study. BMC Public Health. 2015;15(1):1007.

14. Guirindola Mildred O, Maniego Ma Lynell V, Silvestre Catherine J, S ACC. Determinants of meeting the minimum acceptable diet among Filipino children aged 6-23 months. Philipp J Sci. 2018;147(1):75-89.

15. Owen N, Mhone Thomas G, NP AM. Factors associated with complementary feeding practices among children aged 6-23 mo in Malawi: an analysis of the demographic and health survey 2015-2016. Int Health. 2018;10(6):46679 .

16. Emmanuel UE, Olukemi A. Complementary feeding practices among mothers and nutritional status of infants in Akpabuyo Area, Cross River State Nigeria. SpringerPlus. 2016;5(1):2073.

17. Abebe Z, DesseHaki G, Kaleab B. Health extension workers' knowledge and knowledge-sharing effectiveness of optimal infant and young child feeding are associated with mothers' knowledge and child stunting in rural Ethiopia. Food Nutr Bull. 2016;37(3):353-63. https://doi.org/10.1177/03795721166512 09.

18. Chane MT, Bitew WS, MekonenYimer T, Fekadu MW. Meal frequency and dietary diversity feeding practices among children 6-23 months of age in Wolaita Sodo town, Southern Ethiopia. J Health Popul Nutr. 2017:36(1):18.

19. Issaka Abukari I, Agho Kingsley E. Burns Penelope, page Andrew, Dibley Michael J. determinants of inadequate complementary feeding practices among children aged 6-23 months in Ghana. Public Health Nutr. 2015; 18(4):669-78. https://doi.org/10.1017/S1368980014000834.

20. Alex Mokori, Hettie Schonfeldt and sheryl L Hendriks. Child factors associated with complementary feeding practices in Uganda. South African South Afr J Clin Nutr. 2017;30(1):7-14.
21. Macharia Jacqueline Wairimu. Feeding practices and nutrition status among children aged 6-23 months after discharge from supplementary feeding program in Isiolo County. Kenya Food Sci Nutr Res. 2019;2(2):1-6.

22. Micha R, Mannar V, Afshin A, Allemandi L, Baker P, Battersby J, et al. 2020 Global nutrition report: action on equity to end malnutrition. 2020.

23. Getu G, Gudina T. Minimum acceptable diet and factors associated with it among infant and young children age 6-23 months in north Shoa, Oromia Region, Ethiopia.Int J Homeopath Nat Med. 2019;5(1):1-7.

24. Abdurahman A, Eshetu E, H M. Magnitude and determinants of complementary feeding practices in Ethiopia: A systematic review and meta-analysis. Heliyon. 2019

\section{Publisher's Note}

Springer Nature remains neutral with regard to jurisdictional claims in published maps and institutional affiliations.
Ready to submit your research? Choose BMC and benefit from:

- fast, convenient online submission

- thorough peer review by experienced researchers in your field

- rapid publication on acceptance

- support for research data, including large and complex data types

- gold Open Access which fosters wider collaboration and increased citations

- maximum visibility for your research: over $100 \mathrm{M}$ website views per year

At BMC, research is always in progress.

Learn more biomedcentral.com/submissions 